\title{
Sobre la curaduría y su papel en la divulgación
}

Curatorship and scientific dissemination

\section{Alejandra Mosco Jaimes}

Escuela Nacional de Conservación, Restauración y Museografía (ENCRYM),

Instituto Nacional de Antropología e Historia (INAH), México

alejandra_mosco@inah.gob.mx

\section{Resumen}

El presente REPORTE analiza tanto el concepto de curador como la práctica curatorial desde la perspectiva de algunos textos publicados en décadas recientes, en distintos ámbitos institucionales y académicos de nuestro país. Aquí, tras distinguir dos nociones sobre la curaduría: la técnica y la académica, se hace hincapié en la importancia de la figura del curador como divulgador, al tiempo que se resalta el papel clave del guion curatorial en esa función.

\section{Palabras claves}

curador; curaduría; México; divulgación; guion curatorial

\section{Abstract}

This CHRONICLE examines recently published texts of different institutional and academic fields in Mexico about the concepts of curator and curatorship. It focuses on the importance of the curator as a spokesperson and scientific adviser-distinguishing the notions of technique and academics- while emphasizing the key role of the curatorial script.

\section{Key words}

curator; curatorship; Mexico; scientific dissemination; curatorial script 


\section{Introducción}

El I objeto de este REPORTE es reflexionar acerca tanto del papel del curador como de la naturaleza de la práctica curatorial, y poner el énfasis en la tarea de divulgación. En el primer apartado presento de manera muy concisa el entorno en que el término curaduría se ha abordado en América Latina durante las décadas recientes. En el segundo analizo el papel del curador como divulgador, así como la propuesta del guion curatorial como el "puente" entre los guiones científico/académico y museográfico, ejercicio que cierro con unas breves reflexiones finales.

De inicio, conviene explicar que parto de la premisa de que el concepto curaduría es, en principio, ambiguo, pues no nace propiamente en el museo ni se aplica únicamente en su contexto. Basta con revisar cualquier diccionario para advertir que su significado abunda en el terreno no especializado y no se lo asocia con el campo museístico; por ejemplo, el de la Real Academia Española (RAE 2001:717) define curador como aquel que está a cargo de un menor, el que cuida o cura algo; o quien cura lienzos, carnes, pescados, etc. No es vano este asunto, pues refleja que todavía en el 2001 la máxima autoridad en nuestro idioma no incluía discusiones o planteamientos sobre terminología clave asociada con el museo. ${ }^{1}$ Por ello, aquí he decidido empezar, con base en algunos textos especializados suscritos por autores mexicanos y latinoamericanos en décadas recientes, una sucinta discusión sobre lo que se ha definido como curador, curaduría y práctica curatorial.

\section{Consideraciones sobre las nociones de curador y curaduría}

Al analizar algunos textos especializados en el ámbito museológico sobresalen dos nociones distintas para explicar curaduría: por un lado, las que Ilamaríamos de tipo "técnico", es decir, que precisan el término mediante las actividades del curador, $y$, por el otro, aquellas que sostienen un posicionamiento "reflexivo" sobre la práctica curatorial.

Un ejemplo de la primera categoría lo encontramos en el ensayo de Iker Larrauri, museógrafo mexicano de gran trayectoria - aunque no se le reconoce propiamente como curador-, titulado "Curas, curanderos y curadores en los museos" (2007:92), en el que contextualiza la palabra curaduría en el caso de México, y señala que los vocablos curador y curaduría se incorporaron a la mu-

\footnotetext{
${ }^{1}$ En su vigesimotercera edición, de 2014, consigna "Persona que cura algo; como lienzos [los blanquea], pescados, carnes, etc.". En el campo de los museos tampoco existe un vocabulario universal consensuado sobre términos aplicables a la museología; por ejemplo, lo que aquí en México entendemos como curador, en España se denomina convencionalmente conservador.
}

seología en la década de los años setenta del siglo XX, mas "no fueron aceptados con facilidad ni con simpatía porque sus significados más conocidos están asociados a actividades ajenas a la labor de los museos, como son la medicina y el sacerdocio católico" (Larrauri 2007:92). En el mismo texto esclarece de manera puntual las actividades "técnicas" del curador, a seguir:

El curador es el investigador que conoce y estudia los temas y los materiales que dan motivo a la existencia y determinan las funciones de un museo. Para esto aplica los conocimientos de su especialidad y contribuye de esta manera a la conservación y divulgación de estos temas y materiales. Sus actividades se orientan en dos sentidos, por una parte, la organización, control y manejo de las piezas que forman las colecciones, y por otra, su estudio, identificación y clasificación, para conocer e interpretar el significado de éstas. En consecuencia, el curador además de tener a su cargo el cuidado de las colecciones, es quien sistematiza y conforma los contenidos temáticos y materiales de las exposiciones. Asimismo, tiene indirectamente injerencia y responsabilidad en los contenidos temáticos de los comunicados informativos y promocionales que emite el museo y en los programas educativos y de divulgación que realiza.

Cabe destacar que Larrauri (2007:89-94), amén de enunciar que la labor del curador está orientada básicamente a la investigación y la gestión de colecciones, concibe la divulgación del conocimiento como parte de las competencias de la curaduría.

En mi experiencia esta noción de tipo "técnico" del $\mathrm{cu}$ rador, que principalmente lo entiende como investigador, es común en museos mexicanos de corte histórico, arqueológico y de ciencias. En otro aspecto, vale subrayar que en esta última tipología museológica el curador atiende un propósito abiertamente educativo (Eduteka 2015).

Alternativamente, la noción de tipo "reflexivo" aparece con más frecuencia en el ámbito bibliográfico del arte moderno; en el contemporáneo, en particular. Félix Suazo, experto en arte, la expresa así en "El (sano) oficio de curar" (2007:78-81):

Una de las figuras profesionales más extravagantes y ambiguas en el contexto de la cultura plástica contemporánea es la del curador de exposiciones. A menudo confundido por los profanos como un terapeuta raro venido a menos para curar no se sabe qué patología del arte y otras veces entendido, sencilla y llanamente, como un sujeto que organiza exposiciones (Suazo 2007:s. p.).

La ambigüedad a la que alude Suazo (2007:s. p.) queda resuelta de forma casi irónica, al plantear que el curador es

[...] una suerte de sanador estético cuya función básica consiste en el diagnóstico de tendencias, inclinaciones y 
tensiones propias de la cultura y el arte de nuestro tiempo [...] un hacedor de lecturas, un inventor de hermenéuticas que incentiva la complicidad entre los artistas, las obras y sus destinatarios potenciales.

Así, de este autor recupero la noción del curador como organizador de exposiciones e interlocutor de la experiencia artística.

En el ámbito de los museos de arte en México, el perfil del curador aparece de manera aún más compleja y múltiple: un experto en arte, cuya función curatorial se orienta a ofrecer propuestas de resignificación de la obra a través de su visión y lectura personal ( $v$. gr., Garavito 2013). ${ }^{2}$ Asimismo, mientras que en los museos históricos o de ciencias el curador tiende al anonimato, en los de arte moderno y contemporáneo suele ser el protagonista de la exposición, algunas de las veces incluso más allá del propio artista o artistas, y juega uno o varios roles, ya sea como el experto en historia del arte, como el crítico o como el dealer, o comerciante de arte (cfr. Boesch y Sterpi 2013). ${ }^{3}$

Cuauhtémoc Medina (2001:7-8), crítico mexicano de arte moderno y contemporáneo, apunta una visión de la curaduría que se alinea con lo anteriormente postulado. Si bien señala que no es posible precisar en qué momento el latinismo curator, o "guardián legal", se incorporó al lenguaje de los museos anglosajones para designar a sus encargados de exhibir y coleccionar, destaca la capacidad del curador de mantenerse en los ámbitos de los derechos público y privado, y, de la misma manera, su competencia como:

[...] organizador de exhibiciones de la galería pública o el agente intelectual/decorativo de la galería privada, y el promotor ya no de la institución estatal, sino del mundo del arte y su mercado. Como nueva profesión, el curador es fruto de la división del trabajo y del mapa epistemológico. A la vez es el amalgamamiento de una serie de funciones anteriormente diversificadas en un territorio vago, cambiante, móvil y multifuncional. En tanto el universo conceptual del crítico de arte, historiador, museógrafo, artista, comisario de exhibiciones, pseudo-connoisseur, diseñador de exhibiciones, administrador, galerista, publicista, direc-

\footnotetext{
${ }^{2}$ En exposiciones de este tipo, muchas veces existe una gran tensión entre la figura del curador y el artista, pues, tratándose de arte en el que el artista aún se encuentra vivo, la discusión se centra entre si el curador ofrece la lectura que el artista originalmente se planteó sobre su obra; por ello, también es común encontrar exposiciones "curadas" por el propio artista (Garavito 2013).

${ }^{3}$ Cfr. The Art Collecting Legal Handbook, de Boesch y Sterpi (2013), que compila ensayos y entrevistas de diversos curadores en el mundo, quienes analizan principalmente los aspectos legales de las piezas y colecciones artísticas. Ahí también se perfilan las dinámicas y tensiones que existen entre artista, dealer [comerciante], coleccionista y curador, así como algunas reflexiones cuando un personaje lleva a cabo una, varias o todas estas funciones.
}

torio telefónico, guerrillero y activista cultural, cajuelera y pensador nos plantea el campo ordenado de subdivisiones disciplinarias de la modernidad, la ambigüedad y plurifuncionalidad de la noción "curador" nos lanza de lleno en el mélange postmoderno de la confusión disciplinaria.

De esta idea de curaduría, con todo y sus múltiples competencias, complejidades e imprecisiones, recojo la del curador como diseñador de exposiciones y activista cultural. He de señalar que otros autores han subrayado que el ejercicio curatorial siempre tiene su origen en una postura o intención que se ha perfilado como parte de un compromiso social. Ésta es la perspectiva de Adriana Higuera (2005:5) en su ensayo "Espacios de representación y mediación curatorial: un reto para el encuentro" advierte que: "si el museo tiene una función social, y la curaduría se lleva a cabo en dicho espacio, es claro concluir que la práctica curatorial no se encuentra exenta de la misma función".

Oliver Debroise, ${ }^{4}$ historiador y crítico de arte, fue, como lo recuerda Medina (2008:s. p.), el "inventor de la noción del curador como político cultural izquierdista, virus crítico de la globalización y agente de una continua efervescencia intelectual" en México.

Según aquí se ha mostrado, en nuestro país se han planteando diferentes ideas sobre lo que comprende el papel del curador, desde la mera organización de exposiciones hasta el activismo político. Por mi parte, pongo de relieve el compromiso social del curador, justamente aquel que por principio tendría que ver con la mediación al acceso de los contenidos museológicos. Es en consideración a la gran diversidad de públicos y la necesidad de facilitar que éstos comprendan los discursos museológicos como quisiera ahora enfatizar el deber del curador como divulgador.

\section{El curador en el papel de divulgador}

Para iniciar, defino la curaduría como la disciplina que se encarga del estudio de la creación artístico-cultural y de los saberes reunidos en el museo a través de la identificación, clasificación, documentación, catalogación, investigación, selección y ordenamiento de sus colecciones. Su finalidad consiste en conceptualizar y desarrollar contenidos $^{5}$ para las exposiciones, con un sentido de co-

\footnotetext{
${ }^{4}$ Oliver Debroise fue responsable de la conformación del acervo del Museo Universitario de Arte Contemporáneo (MUAC). Cuauhtémoc Medina (2008:s. p.) lo recuerda así: como "uno de los más feroces críticos y curadores de arte de México, como un novelista homosexual que exploró el entrecruce entre historia, violencia y deseo, como un agente cultural igualmente devastador en derruir mitos y suscitar transformaciones institucionales, es poco".

${ }^{5}$ Entiéndase en el sentido más amplio "desarrollo de contenidos", o discurso, que también será la base para el resto de los programas de divulgación asociados con la exposición: catálogos, talleres, audiovisuales, folletos, guías, actividades complementarias, etcétera.
} 
municación-divulgación dirigida a los públicos, por medio de la interpretación de sus valores y significado. Con base en lo anterior, el curador es, en esencia, un especialista en alguna disciplina: humanidades, ciencias o arte, dependiendo de la naturaleza del museo. De esto surge un nuevo planteamiento: ¿cuándo o cómo la investigación científica o académica vinculada con los museos se convierte en curaduría y ésta, a su vez, en un trabajo de divulgación?

Para empezar a responder este cuestionamiento es necesario diferenciar dos términos que comúnmente se confunden y utilizan de manera casi indistinta: divulgar y difundir. Manuel Gándara Vázquez (2001:16), arqueólogo mexicano especializado en divulgación del patrimonio arqueológico, hace una observación valiosa al respecto:

Cuando difundimos, lo hacemos entre pares, es decir, entre arqueólogos u otros especialistas, como cuando publicamos en revistas especializadas. El lenguaje puede ser técnico, porque asumimos que el lector lo entiende. Podemos obviar también cuestiones de contexto o de antecedentes, porque los colegas los conocen, e incluso quizá les ofenda si los incluimos. En la divulgación, sin embargo, le hablamos al gran público. El lenguaje es aquí clave: la gente no domina la terminología ni conoce el contexto o los antecedentes.

Debemos considerar que los especialistas de un determinado campo del saber rara vez tienen conocimientos teórico-metodológicos que los capaciten para realizar tareas de divulgación en museos. ${ }^{6}$ Asimismo, es de notar, por un lado, que en decenios recientes en gran cantidad de museos sus áreas de comunicación o servicios educativos han sido las responsables de la función de divulgar o "hacer más accesibles" los contenidos de las exposiciones a los diferentes públicos, y, por el otro, que esta tarea se lleva a cabo regularmente como un trabajo posterior o alterno a la curaduría.

Es mi convicción que la investigación que se produce en un museo debería contar no sólo con todo el rigor académico y/o científico sino también con un enfoque propiamente museológico, es decir, de conservación, comunicación, exposición y divulgación. ${ }^{8}$ Por lo tanto, el

\footnotetext{
${ }^{6}$ Derivo esta observación de mi experiencia profesional en los últimos años, ya que mi trabajo se ha centrado, justamente, en capacitar a especialistas en el campo de la divulgación patrimonial desde la metodología de la interpretación temática, tradicional de la escuela americana (cfr. Mosco 2012).

${ }^{7}$ De hecho, en el ámbito del arte, principalmente, el contemporáneo, este fenómeno se agudiza, pues el curador, "el experto", no necesariamente trabaja con un sentido de comunicar, explicar o divulgar, sino tan sólo con el postulado de que el arte "se exprese por sí mismo"; no obstante, sin los referentes necesarios, los discursos resultan muy complejos y alejados del público común.

${ }^{8}$ Esta visión se ha empezado a incorporar en el Instituto Nacional
}

investigador del museo estaría obligado, como parte de su compromiso social, a traducir y hacer comprensibles los fenómenos u objetos de estudio tanto para la comunidad especializada como para un vasto público. Desde luego esto, en la medida en que implica que el investigador articule estrategias de divulgación que puedan cristalizarse en el máximo espacio museográfico: la exposición que representa un esfuerzo extra.

Ahora bien, el trabajo de investigación tradicionalmente se vierte, o "convierte", en un guion científico, museológico o académico. ${ }^{9}$ Esta cadena de producción intelectual se ha documentado en el tema al que se consagró el número 52 de la Gaceta de Museos: "Aspectos del trabajo curatorial" (2012), que aborda la función del investigador como curador desde la perspectiva del Instituto Nacional de Antropología e Historia (INAH). Al respecto coincido con la visión comunicativa de María Eugenia Sánchez Santa Ana (2012:24), quien subraya que el investigador-curador debe tener no sólo la habilidad de sintetizar su investigación "sino también de traducirla a un lenguaje museal, es decir, de plasmarla en guiones científicos, considerados como los contenedores de la información recopilada, sistematizada y analizada que el museo (emisor) ha de transmitir (mensaje) al visitante (receptor)".

Es relevante apuntar que, al hablar de las funciones curatoriales, los autores anteriormente citados no señalan entre las competencias del curador la actividad comunicativa ni la producción de un guion curatorial. Comparativamente, Sánchez Santa Ana (2012:24-25), aunque habla del guion científico como un paso para la creación del proyecto museográfico, no se refiere exactamente a la curaduría como un campo diferenciado, como tampoco a la existencia de un guion curatorial. ${ }^{10}$

Sin embargo, considero de la mayor relevancia la existencia de un puente entre los guiones científico o académico (investigación especializada, selección de obra, cuando existe) y museográfico (diseño arquitectónico, espacial, grafico e industrial); este enlace es el guion propiamente curatorial, que sintetiza los contenidos científicos o académicos, o "traduce" la terminología especializada a un lenguaje claro y comprensible (plasmado, primordialmente, en las cédulas), así como la selección de obra (cuando exista) y la articulación de las estrategias interpretativas de divulgación para que los contenidos resulten

de Antropología e Historia (INAH); de hecho, Carlos Vázquez Olvera (1993:217), historiador de la museografía mexicana, ha señalado que el profesional adscrito a la red de museos de dicho instituto se denomina investigador-curador.

${ }^{9}$ Cabe indicar que en la comunidad museológica tampoco existe consenso sobre este instrumento ni acerca de sus características.

${ }^{10}$ Para Sánchez Santa Ana (2012:24-25), el guion científico, una vez enriquecido con las propuestas del investigador y acabado con el material de difusión, "se presentará al equipo de museografía, el cual, para su puesta en escena, interpretará la información plasmada en él y elaborará el proyecto museográfico". 
relevantes y significativos para todos los públicos. Cuando señalo estrategias interpretativas me refiero a que el curador con la perspectiva de divulgador ha de aplicar una serie de técnicas, de las cuales aquí resaltaré al menos dos. Primeramente, debe optar por el uso de frases o mensajes claros, cortos y relevantes que resuman el propósito de la exposición y sus contenidos (Ham 2013), esto es, lo que en la tradición de la interpretación temática se Ilama tesis (cfr. Gándara 2001:67-70). Enseguida, ha de poner de relieve el planteamiento de objetivos al menos en tres sentidos: conocimiento, emoción y acción (Veverka 2011:71-78). Mi propuesta en este sentido es que si el objetivo de conocimiento que encarna la exposición está claro, aún debemos cuestionarnos qué queremos que la gente aprehenda. En otras palabras, a los curadores no ha de bastarnos brindar información y desarrollar los temas para la exposición, sino plantearnos que ésta no pierda la misión de estimular una emoción en el público. Vale entonces preguntarse, como parte del guion curatorial, qué se quiere que la gente sienta y qué reacciones (empatía, orgullo, admiración, sorpresa, enojo, tristeza, etc.) se pueden generar a partir de los contenidos museográficos. Los curadores debemos plantearnos, asimismo, propósitos varios en cuanto a acción: ¿qué se quiere que la gente haga (con esta información, después de su visita)?, ¿qué actitudes se desea fomentar?, ¿cómo le puede ser útil al público este conocimiento? Estos y otros criterios propios de la interpretación temática - hacer analogías, utilizar referentes sencillos y comunes a un público amplio (Mosco 2012:231-300)— podrán entonces vislumbrarse como nuevos horizontes de la curaduría.

\section{A manera de conclusión}

Entiendo que aún sea debatible el hecho de pensar la curaduría como una disciplina, pues en la realidad se ha llevado a cabo más como una práctica, "la curatorial", la cual, según lo ha esclarecido este breve REPORTE, integra una serie de saberes muy específicos que, aunque se nutren de diversos campos disciplinarios del conocimiento, en su conjunto son sólo aplicables al ámbito museal. Ello significa que la curaduría puede sostenerse como área de especialización.

En esta contribución he querido enfatizar, pues, el papel del curador como divulgador dentro de esta especialización. Como últimas palabras, considero que este planteamiento es congruente con el objeto social del museo. Es importante reflexionar que el hacer accesibles los discursos a los públicos en todos los ámbitos del museo requiere múltiples esfuerzos. Sin embargo, será de mayor relevancia comenzar desde la curaduría, esto es, precisamente ahí donde se conceptualizan y desarrollan los contenidos que dan sentido a la actividad museal.

\section{Referencias}

Boesch, Bruno y Massimo Sterpi (coords.) 2013 The Art Collecting Legal Handbook, Londres, Thomsom Reuters.

Eduteka

2015 "Educadores de museos en línea: los usuarios finales como intérpretes", documento electrónico disponible en [http://www.eduteka.org/Profesor5.php], consultado en octubre del 2015.

Gándara Vázquez, Manuel 2001 "Aspectos sociales de la interfaz con el usuario. Una aplicación en museos", tesis de doctorado en diseño, México, UAM-A.

en prensa "De la interpretación temática a la divulgación significativa del patrimonio arqueológico", en Manuel Gándara Vázquez y María Antonieta Jiménez Izarraráz (eds.) La interpretación del patrimonio cultural: pasos hacia una divulgación significativa en México, México, ENCRyMINAH, 10-48.

Garavito, Ramiro 2013 "Curadurías y curadores", en La Razón, documento electrónico disponible en [http://www.la-razon.com/ index.php?_url=/suplementos/tendencias/Curadurias-curadores_0_1868213253.html], consultado en noviembre del 2015.

Ham, Sam H.

2013 Interpretation: Making a Difference on Purpose, Golden/EUA, Fulcrum Publishing.

Higuera, Adriana

2005 "Espacios de representación y mediación curatorial: un reto para el encuentro", ponencia presentada en el Tercer Seminario de Estudios Culturales: Museos como Zonas de Contacto, La Paz, Universidad de Baja California (UBC), s. p.

Larrauri, Iker 2007 "Curas, curanderos y curadores en los museos", Diario de Campo "Iker Larrauri: 50 años en la museografía", 41:89-94.

Medina, Cuauhtémoc

2001 "La más indirecta de las acciones: bastardía de orígenes, traición a la patria y oportunismo militante del juego curatorial post-mexicano", ponencia presentada en el ciclo Ambulancia del Centro Nacional de las Artes, 18 de julio, México, Museo Carrillo Gil y Escuela Nacional de Pintura, Escultura y Grabado, "La Esmeralda", 1-20, documento electrónico disponible en [http://issuu.com/cuauhtemocmedina/docs/vendepatriasres], consultado en octubre del 2015.

2008 "Debroise. Ondas expansivas (1952-2008)", documento electrónico disponible en [http://reforma. vlex.com.mx/vid/cuauht-moc-debroise-ondas-expansivas-202248099], consultado en agosto del 2015. 
Mosco, Alejandra

2012 "Metodología interpretativa para la formulación y desarrollo de guiones para exposiciones", tesis de maestría en museología, México, ENCRYM-INAH.

RAE

2001 "Curaduría", Diccionario de la lengua española, Madrid, Real Academia Española (RAE), 717.

Sánchez Santa Ana, María Eugenia

2012 "Funciones del investigador-curador en la reestructuración de una sala de exposición en el Museo Nacional de Antropología", Gaceta de Museos 52:24-29.

Suazo, Félix

2007 "El (sano) oficio de curar", Estilo 1 33:78-81.

Veverka, John

2011 Interpretive Master Planning, Volume 1: Strategies for the New Millennium, Edinburgo, MuseumsEtc Ltd.

\section{Síntesis curricular del/os autor/es}

\section{Alejandra Mosco Jaimes}

Escuela Nacional de Conservación, Restauración y Museografía (ENCRYM),

Instituto Nacional de Antropología e Historia (INAH), México

alejandra_mosco_j@encrym.edu.mx

Maestra en museología (Escuela Nacional de Conservación, Restauración y Museografía [ENCRyM], Instituto Nacional de Antropología e Historia [INAH], México), licenciada en historia (Escuela Nacional de Antropología e Historia [ENAH-INAH], México). Ha trabajado en proyectos de investigación y divulgación de sitios patrimoniales a cargo del INAH. Ha sido curadora de exposiciones permanentes y temporales para instituciones públicas y privadas. Fue merecedora del Premio INAH "Miguel Covarrubias" 2013 por la mejor tesis de maestría en el área de museografía e investigación en museos, por una propuesta metodológica para desarrollar guiones para exposiciones con una perspectiva interpretativa. Actualmente es profesora de tiempo completo en la maestría en museología y la especialidad en museografía, miembro del cuerpo académico Programa para el Desarrollo Profesional Docente (PRODEP), con la línea de investigación "Estudios de patrimonio y museos" en la ENCRYM-INAH. Imparte cursos en diversas universidades e instituciones, como la Universidad Nacional Autónoma de México (UNAM), la ENAH, la Universidad Autónoma del Estado de México (UAEM), la Universidad Autónoma de Yucatán (UADY), todas en México y la Universidad Autónoma de Colombia

Postulado/Submitted 11.11.2014

Aceptado/Accepted 04.12.2015

Publicado/Published 31.03.2016 